\title{
Wissenschaftsgeschichte
}

\section{Ernst Haeckel und die Natur als Künstlerin}

\section{UWE HOBFELD}

INSTITUT FÜR ZOOLOGIE UND EVOLUTIONSFORSCHUNG, UNIVERSITÄT JENA

DOI: $10.1007 / \mathrm{s} 12268-019-1035-9$

(C) Springer-Verlag 2019

Der Zoologe Ernst Haeckel (1834-1919), der in diesem Jahr seinen 100. Todestag begeht, zählt zu den bekanntesten, zugleich aber auch umstrittensten Naturforschern des 19. und beginnenden 20. Jahrhunderts (Abb. 1). Als einer der frühesten Anhänger und streitbarsten Verfechter der Darwin'schen Evolutionstheorie stellt er eine Zentralfigur in der Frühgeschichte des Darwinismus dar. Er war aber nicht nur ein bedeutender Naturwissenschaftler, sondern verfügte auch über eine außergewöhnlich ästhetische Betrachtungsweise biologischer Phänomene [1].

Charakteristisch für Haeckels letzte zwei Lebensjahrzehnte war - neben den philosophischen Einlassungen - seine künstlerische Veranlagung, die nicht nur in der ästhetischen

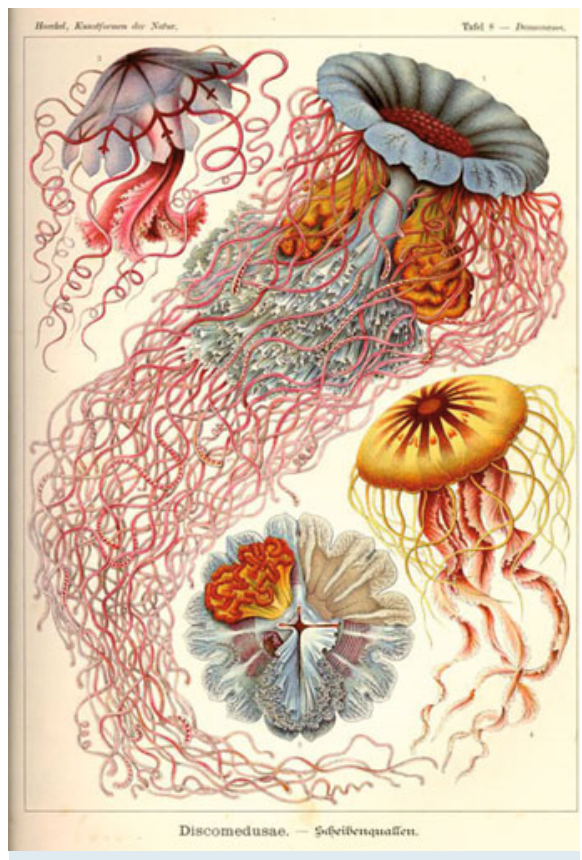

A Abb. 2: Tafel 8 „Discomedusae“ aus Ernst Haeckels Buch Kunstformen der Natur von 1904. Haeckel benannte die Art in der Mitte als Desmonema Annasethe (heute: Cyanea annasethe Haeckel, 1880) nach seiner Frau Anna Sethe, die 1879 verstarb. Bild: gemein frei, https://commons.wikimedia.org/ wiki/File:Haeckel_Discomedusae_8.jpg.
Gestaltung seiner Abbildungen in den systematischen Monografien, sondern vor allem auch in etwa 1.200 Aquarellen und Skizzen zum Ausdruck kam, die während seiner zahlreichen Reisen an das Mittelmeer, zu den Kanarischen Inseln, das Rote Meer, Nordafrika, Russland, Ceylon, Java und Sumatra oder in seinem Heimatort Jena entstanden. Bereits als 28-Jähriger publizierte er eine fast 600 Seiten umfassende Abhandlung (Monographie der Radiolarien), wo 35 Tafeln mit selbst gezeichneten Radiolarien integriert waren [2]. Diesen so bizarr anmutenden, symmetrischen Kleinstlebewesen widmete er 1887 ein weiteres umfassendes Werk von 1.800 Seiten mit 140 Tafeln (Beschreibung von über 4.000 verschiedenen Arten und 739 Gattungen) [3].

Das eindrucksvollste und zugleich einflussreichste Dokument seiner ästhetischen Naturbetrachtung stellt aber das in zehn Lieferungen zu je zehn Bildtafeln zwischen 1899 und 1904 erschienene Tafelwerk Kunstformen der Natur dar [4] (Abb. 2). Mit diesem Werk wollte er „weiten gebildeten Kreisen den Zugang zu den wunderbaren Schätzen der Schönheit öffnen, die in den Tiefen des Meeres verborgen oder wegen ihrer geringen GröBe nur durch das Mikroskop erkennbar“ waren. Gleichzeitig verfolgte er auch ein wissenschaftliches Ziel: die systematische Ordnung sämtlicher Formengruppen der Natur, um so auch den Laien „den Einblick in den Wunderbau der eigentümlichen Organisation dieser Formen zu erschließen“.

In der Ästhetik sah Haeckel die Aufgabe, die „Gesetzmäßigkeiten zu erforschen, die dieser Lust und Freude am Schönen“ zugrunde lagen [5]. Seine biomorphe Ästhetik fußte dabei auf seiner Suche nach verborgenen universalen Prinzipien der Natur, die in symmetrischen Ordnungen Sichtbarkeit erlangen sollten.

Die enorme Formenfülle und Schönheit der für Laien damals noch weitgehend unbekannten Tierformen inspirierte viele, sich vom Historismus lösende Künstler des Jugendstils, sich diesen „Urformen des Lebens“ in Gestalt der Einzeller, Quallen und Polypen zuzuwenden. So lassen sich unter anderem bei

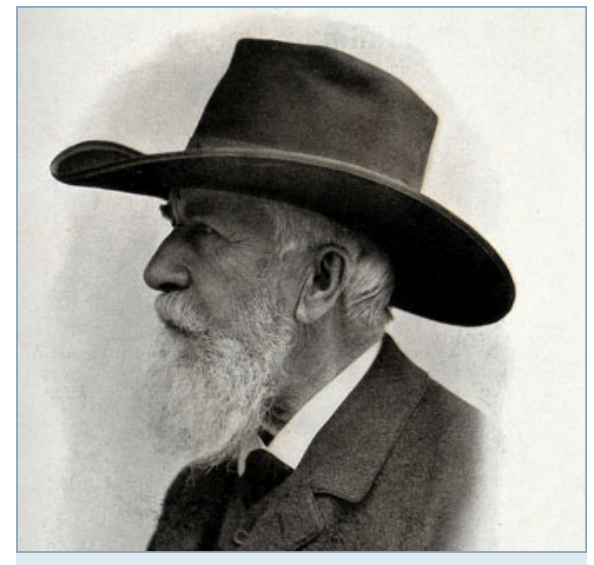

A Abb. 1: Ernst Heinrich Philipp August Haeckel. Bild: Wellcome Collection, https://wellcomecollection.org/works/ t35e5ema, CC BY 4.0.

Hermann Obrist (1862-1927), einem Begründer des deutschen Jugendstils, und dem Glaskünstler Louis Comfort Tiffany (1848-1933) Einflüsse auf die ornamentale und abstrakte Gestaltung nachweisen. Der Pariser Architekt René Binet (1866-1911) war ebenfalls von der Vielfalt und Symmetrie der von Haeckel in seinen wissenschaftlichen Monografien und in den Kunstformen der Natur dargestellten Meerestierformen fasziniert und gestaltete die monumentale Eingangspforte der Pariser Weltausstellung 1900 in Form einer riesigen Radiolarie [6].

\section{Literatur}

[1] Hoßfeld U (2010) Ernst Haeckel. Orange Press, Freiburg i. Br.

[2] Haeckel E (1862) Die Radiolarien (Rhizopoda radiaria). Eine Monographie. G. Reimer, Berlin

[3] Hackel E (1887) Report on the Radiolaria collected by H. M. S. Challenger. Longmans \& Co., London

[4] Haeckel E (1899-1904) Kunstformen der Natur. Bibliographisches Institut, Leipzig

[5] Haeckel E (1905) Die Lebenswunder. A. Kröner, Stuttgart, S. 210, 214

[6] Binet R (1902) Esquisses décoratives. Librairie Centrale des Beaux-Arts, Paris

\section{Korrespondenzadresse:}

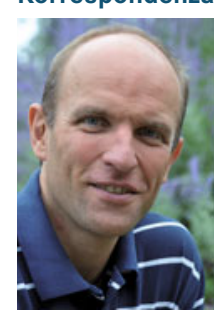

Prof. Dr. Uwe Hoßfeld Arbeitsgruppe Biologiedidaktik Institut für Zoologie und Evolutionsforschung Fakultät für Biowissenschaften Friedrich-Schiller-Universität Jena Am Steiger 3, Bienenhaus D-07743 Jena

Tel.: 03641-9-49491 uwe.hossfeld@uni-jena.de 